\title{
The Digital Divide in Technologies for Autism: Feasibility Considerations for Low- and Middle-Income Countries
}

\author{
Aubrey J. Kumm ${ }^{1} \cdot$ Marisa Viljoen $^{1} \cdot$ Petrus J. de Vries $^{1}$ (I) \\ Accepted: 11 May 2021 / Published online: 13 June 2021 \\ (c) The Author(s), under exclusive licence to Springer Science+Business Media, LLC, part of Springer Nature 2021
}

\begin{abstract}
Digital technologies have the potential to empower individuals with autism and their families. The COVID-19 pandemic emphasized and accelerated the drive towards technology for information, communication, training, clinical care and research, also in the autism community. However, $95 \%$ of individuals with autism live in low- and middle-income countries (LMIC) where access to electricity, internet and the ever-increasing range of digital devices may be highly limited. The World Bank coined the term 'the digital divide' to describe the disparities in access to digital technologies between high-income and LMIC contexts. Here we evaluated the feasibility of six emerging technologies for autism spectrum disorders, and reflected on key considerations for implementation in LMIC contexts to ensure that we do not inadvertently widen the pre-existing digital divide.
\end{abstract}

Keywords Digital technology $\cdot$ Autism spectrum disorder $\cdot$ Digital disparities $\cdot$ Low-resource contexts $\cdot$ Africa $\cdot$ India

\section{Introduction}

Autism spectrum disorders (ASD) are neurodevelopmental disorders characterised by a wide range of features, including difficulty with social interaction and communication, restricted interests, and stereotyped behaviours (American Psychiatric Association, 2013). As a group people with ASD have a broad range of abilities, allowing some to lead independent and productive lives with varying levels of support, while others are severely affected by manifestations that may persist throughout the lifespan (Farley et al., 2009). However, there is growing evidence that early identification and treatment and a range of other interventions can reduce the manifestations and improve the functional outcomes of ASD for many affected individuals (Bradshaw et al., 2015; Dawson et al., 2012; Rogers \& Dawson, 2010).

Given the global prevalence of ASD estimated in excess of 1\% (Elsabbagh et al., 2012; Fombonne, 2009), the World Health Organization recognised ASD as a global public

Petrus J. de Vries

petrus.devries@uct.ac.za

1 Division of Child \& Adolescent Psychiatry, Centre for Autism Research in Africa (CARA), University of Cape Town, 46 Sawkins Road, Rondebosch 7700, Cape Town, South Africa health concern and a major cause of disease burden (World Health Organization, 2013). However, 95\% of individuals with ASD and other developmental disabilities live in low- or middle-income countries (LMIC) (Franz et al., 2017; Olusanya et al., 2018, 2020), where they are typically either undiagnosed or diagnosed much later than those living in high-income countries (HIC), and where they may receive no or very limited intervention and support (Daley, 2004; Lagunju et al., 2014; Pillay et al., 2021). Disparities in access to ASD screening, diagnosis, and treatment in low-resourced communities exist globally (Patel et al., 2008). Factors such as symptom severity, geographic location, socio-economic status (SES), race/ethnicity and culture impact both the age of first assessment and subsequent intervention (Lagunju et al., 2014; Williams et al., 2014).

Over the last 30 years, the rates of ASD and other disabilities have increased most significantly in sub-Saharan Africa (SSA) and in South-East Asia (Olusanya et al., 2018) where the majority of communities face significant challenges to access skilled professionals and appropriate services (de Vries, 2016; Franz et al., 2017; Saxena et al., 2007). Families who live in remote, low-resource areas typically have to travel considerable distances, sometimes for hours or days, for their children and adult family members to receive the services they need (Divan et al., 2012; Mahapatra et al., 2019). The lack of reliable transport infrastructure, shortage 
of trained professionals and lengthy waiting times may result in these visits taking days rather than hours (Daley, 2004; Durkin et al., 2015). Compounding the infrastructural challenges, people living in rural or remote areas of LMIC typically also have limited awareness of and poor knowledge about ASD. This, unfortunately, also includes educational and healthcare professionals (Bakare et al., 2009; de Vries, 2016; Franz et al., 2017; Ruparelia et al., 2014). Lack of knowledge about ASD combined with local cultural and traditional beliefs contribute to social stigma and discrimination, often depriving these already disadvantaged groups of opportunities to improve their health, education and community participation (Harrison et al., 2017; Harrison et al., 2017; Keusch et al., 2006; Michels et al., 2006).

Apart from gaps in clinical care and knowledge, there is also a significant disparity in the proportion of ASD research that has been conducted in LMIC as opposed to HIC settings. Taking sub-Saharan Africa as example, in a comprehensive scoping review Franz et al. (2017) showed that less than $1 \%$ of global ASD research had taken place in Africa. The review by Franz did not directly compare the proportion of research in all LMIC to research from all HIC, but it was clear that the majority of ASD research to date has come from HIC where the minority of people with ASD live.

\section{Emerging Digital Technologies for Autism Spectrum Disorder}

In recent years, there has been a rapid increase in utilising technology for identification, intervention and training to address the various challenges in delivering health and other care to families living with ASD (Grynszpan et al., 2014; Odom et al., 2015; Ploog et al., 2013). Unlike traditional service delivery models (involving highly skilled professionals in one-to-one, in-person sessions), technology allows the possibility to increase access on a large scale at relatively low cost, and to utilise a diverse workforce in local settings where these services are poor or non-existent. Technology therefore has the potential to reduce the disparities in service delivery between HIC and LMIC communities (Naslund et al., 2017).

In a comprehensive review of technologies for ASD, Kientz et al. (2014) identified six main emerging interactive technology platforms (personal computers, robotics, virtual reality, shared active surfaces, sensing technologies, and mobile devices) and used a classification scheme to review these key technologies. The classification included examination of the technology in relation to domain of interest (e.g. social/emotional or language/communication), purpose (e.g. functional assessment or diagnosis/screening), the target end user (e.g. person with ASD or family/caregiver), setting (e.g. home or school), nature of the empirical support (e.g. descriptive or experimental research) and technology maturity (e.g. design, prototype or publicly available). Odom et al., (2015) used similar criteria to examine technology for adolescents with ASD and presented a conceptual framework that identified the 'human' (user), 'activity' (purpose) and 'technology' as key constructs in relation to the 'context' (home, school, community). Building on these earlier reviews, below we present a brief summary of the same technologies and their purpose, settings for use, users and relative cost, using the Kientz et al., (2014) and Odom et al., (2015) frameworks. See Fig. 1 for a visual summary.

\section{Personal Computers}

Personal Computers (PCs) are found in most homes, schools, universities, offices and shops in high-income countries (International Telecommunication Union (ITU), 2010). Computer-based interventions for autistic children have been known since the early 1970s (Colby, 1973; Colby \& Smith, 1971) and used by individuals with ASD and their caregivers to address a wide variety of areas that require attention, from early identification to rehabilitation in a variety of settings (Fig. 1). Today, online platforms (e.g. https:// babynavigator.com, Florida State University, 2021) enable parents to track their child's development prompting them into action if a developmental delay is suspected. Web-based courses (e.g. www.autismnavigator.com, Wetherby et al., n.d.) provide professionals and families access to the latest evidence-based diagnostic tools and intervention techniques. Computer-based training of community-based health care providers has been shown to be as effective as in-person didactic training (Vismara et al., 2009). Even without access to the internet, standard desktop computers with audio-visual presentation software (e.g. PowerPoint) of ASD-related educational material for healthcare professionals, teachers and carers can improve knowledge about ASD. According to Statista (2020a) the average selling price of personal computers in 2019 was US\$632 with prices ranging from around US $\$ 150$ (for refurbished PCs) to several thousand dollars (Statista, 2020a).

\section{Robotics}

Robot-based diagnosis and treatment for ASD has been a rapidly developing area of research in HICs for more than a decade (Dautenhahn \& Werry, 2004; Scassellati, 2007). Researchers investigating robotic interventions for ASD typically report increased engagement and levels of attention when robots are part of the interaction, including individuals who routinely are unlikely or unwilling to interact socially with their healthcare provider and teachers (Diehl et al., 2012; Scassellati, 2007). Robots have been designed to address a variety of behavioural objectives such as joint attention (Kumazaki et al., 2018), social interaction and 
Technology

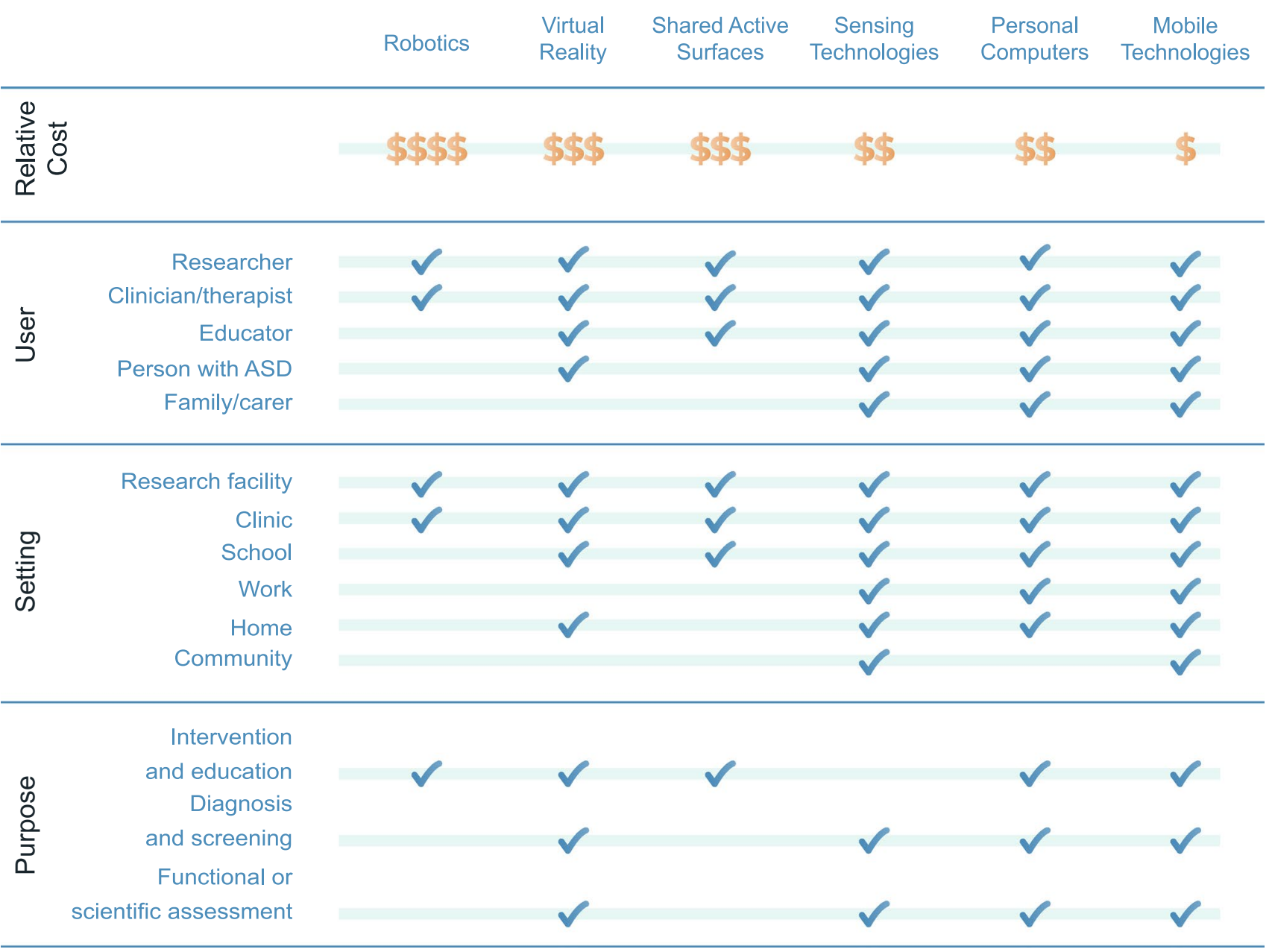

Fig. 1 Summary of emerging technologies for ASD in terms of their purpose, settings for use, potential users, and relative cost

communication skills (David et al., 2020; Kim et al., 2012) in school, clinic or home settings (Dickstein-Fischer et al., 2011, 2017). However, most robotic interventions for ASD have not yet progressed passed the developmental stage and require skilled operators. As a result, their use at present is mostly limited to research and specialised clinical settings. Their costs are substantial, ranging from hundreds to upwards of thousands of U.S. dollars (Boccanfuso et al., 2017; Dickstein-Fischer et al., 2011, 2018) making them the most expensive of the technologies discussed here (Fig. 1).

\section{Virtual Reality}

Virtual Reality (VR) technologies provide realistic safe and repeatable simulated real-world environments wellsuited for teaching individuals with ASD the necessary skills required for independent living and employment
(Parsons et al., 2004; Standen \& Brown, 2005). VR based interventions for ASD have been used for improving social skills (Kandalaft et al., 2013), teaching individuals how to navigate and cross streets (Saiano et al., 2015), use public transport or find a table in a café or restaurant (Parsons et al., 2006). Virtual learning environments have been used for distance education to teach social and communication skills in low or under-resourced areas (Stichter et al., 2014). Head-mounted VR devices (like the Oculus Quest for example-https://www.oculus.com/ compare/) are easily portable, not difficult to operate and can therefore be used in most settings and cost around US\$300 (https://www.oculus.com/compare/, Facebook Technologies, 2021) for the hardware alone. Most stateof-the-art VR technologies for ASD, however, require powerful computers with advanced specifications and access to high speed broadband internet costing thousands rather than hundreds of US dollars (Fig. 1). 


\section{Shared Active Surfaces}

Collaborative Interface (CI) or Shared Active Surface (SAS) technologies are large touch-screen computer-based interactive surfaces that can be placed on tabletops, be operated by more than one person simultaneously and therefore be utilized to enhance social and collaborative face-to-face interaction among multiple users (Dietz \& Leigh, 2001; Travers \& Fefer, 2016) Several published studies have documented the potential of using SAS technologies and cooperative games to improve social skills such as eye contact, sharing of emotions, showing interest toward a partner, and collaborative play in children with ASD (BaumingerZviely et al., 2013; Ben-Sasson et al., 2013; Gal et al., 2016). Multi-user surfaces are not easily transportable due to their size and weight. By its nature, touchscreen devices are not hardwearing and therefore susceptible to damage that could render them unserviceable and very expensive to repair or replace. It is possible that this technology could be useful in very specific settings such as specialist schools, clinics or research facilities (Fig. 1). However, they may not represent a very naturalistic opportunity for assessment or intervention for individuals with ASD. Commercially available multiuser touch tables currently cost from US $\$ 6,500$ excluding any software (POP Communications, 2010).

\section{Sensing Technologies}

Sensing technologies (STs) embedded in everyday accessories such as glasses, wrist watches, clothing, or ultrathin adhesive epidermal patches have been used to collect specific data to identify ASD symptoms (Cabibihan et al., 2017). STs include a variety of devices for tracking eye movement to detect atypical gaze (Constantino et al., 2017; Vidal et al., 2012; Ye et al., 2012), physical activity trackers to detect stereotypical behaviours (Goodwin, et al., 2011; Min \& Tewfik, 2010; Sarker et al., 2018), sensors to detect internal state changes related to stress and anxiety (Fletcher et al., 2010; Goodwin et al., 2006), and sensors to detect atypical prosody and speech (Paul et al., 2005; Warren et al., 2010). However, many wearable physiological and physical activity-sensing devices require direct contact with the skin and may not be tolerated by some children with ASD (Cabibihan et al., 2017). Smart watches (e.g. the Apple Watch) are increasingly utilized both for assisting and monitoring individuals with ASD (Koumpouros \& Kafazis, 2019) in any setting (Fig. 1). Sensing technologies are relatively expensive. The average selling price of smartwatches is around US\$300 (Gartner, 2018; International Data Corporation, 2019) and typically require additional computer software and hardware, as well as highly skilled professionals to analyse and use collected data.
Mobile and Smartphone Technologies

It is estimated that around 74\% of the population in HIC and around $45 \%$ of those living in LMIC own a smartphone while the estimates for tablet ownership are close to 50\% and 20\% respectively (Silver, 2019; Statista, 2020b). Even simple features such as task lists, calendars and address book applications can improve the day-to-day independence of school-going young people with ASD (Gentry et al., 2010; Hedges et al., 2018). Smartphone applications can potentially provide parents and carers with objective early screening (Egger et al., 2018; Kanne, et al., 2018) and intervention tools (Law et al., 2018; Parsons et al., 2019; Rogerson et al., 2019). Using online social media platforms (e.g. WhatsApp, Twitter, Facebook) can for some open the door to social engagement and being part of a community (Hedges et al., 2018; van Schalkwyk et al., 2017). The release of the first Apple iPhone in 2007 set in motion the rapidly evolving novel domain of healthcare referred to as 'mobile health' or 'mHealth'. Currently, there are more than 100,000 mHealth applications ('apps') available globally for download from app stores (Statista, 2021). Despite a paucity of empirical evidence, Smartphone apps for ASD continue to disrupt older technologies in several areas such as communication devices (e.g. WhatsApp) and access to personal medical information. The average selling price of smartphones in 2020 was US\$309 (Statista, 2020b) with a wide range between lower specification smartphones $(<$ US\$100) and ultra-premium phones (> US\$1,000) (International Data Corporation, 2020). Similar to PCs, mobile and smartphone technologies are used by individuals with ASD as well as their caregivers and service providers in most settings and for a wide variety of objectives but at relatively lower cost than many of the other emerging technologies for ASD (Fig. 1).

\section{The 'Digital Divide' Between High-Income and Low/ Middle-Income Countries}

The World Development Report published by the World Bank in 2016 focused on digital technologies in a publication entitled 'Digital Dividends' (World Bank, 2016). The report pointed out that digital technologies have spread rapidly across the globe, but that the 'digital dividends' - the developmental benefits of using these technologies-had lagged behind. The report emphasized that emerging technologies had disproportionately benefited the higher-educated and wealthier sectors of society, and commented that nearly $60 \%$ of the world still had no access to the internet. The internet therefore remains unavailable, inaccessible and unaffordable to a majority of the world's population. "For digital technologies to benefit everyone everywhere therefore requires closing the remaining digital divide, especially 
in internet access" (World Bank, 2016, p. 2). Figure 2 shows a graphic representation of fixed internet users (panel A) and mobile phone subscriptions (panel B) in HIC and LMIC between 2000 and 2017 (data from ITU, 2019 and World Bank, 2020) to illustrate the digital divide. Panel A shows how internet usage increased significantly from 2000 in HIC and LMIC settings, but indicates that the digital divide had increased, rather than reduced, over time with fewer than $40 \%$ of households in LMIC having fixed internet access, in contrast to more than $90 \%$ in HIC. Panel B shows that the digital divide has remained across the last 2 decades in terms of mobile/cellular subscriptions, but indicates that both in HIC and LMIC settings there were more than 90 subscriptions to mobile/cellular networks per 100 inhabitants by the end of 2017.

The COVID-19 pandemic that swept across the globe from the end of 2019, throughout 2020 and into 2021 very rapidly shifted the majority of the world from in-person interactions towards remote interactions using technology for information, communication, teaching and research, including in the ASD community. A collection of commentaries about the impact of COVID-19 on ASD research (Amaral \& de Vries, 2020) showed many examples of technological solutions, pivoting of research towards remote modalities, and so on. However, a few notable examples from lower-resource environments and LMIC expressed concern that the COVID-19 pandemic may simply have magnified pre-existing digital (and social) disparities (see e.g. de Vries et al., and Divan et al., in the Amaral and de Vries commentaries, 2020).

In order to ensure that we do not inadvertently increase the digital divide in the global ASD community, there is therefore a need to reflect on the feasibility of the increasing number and types of digital technologies for ASD. In
Fig. 2 Internet users and mobile phone subscriptions in HIC and LMIC between 2000 and 2017 (data from ITU, 2019 and World Bank, 2020). Panel A shows the percentage of households with access to fixed internet; Panel B shows the number of mobile/ cellular subscriptions per 100 individuals

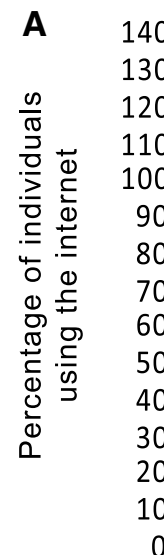

$1 3 0 \longdiv { - }$

$$
=-=\text { LMIC }
$$

B

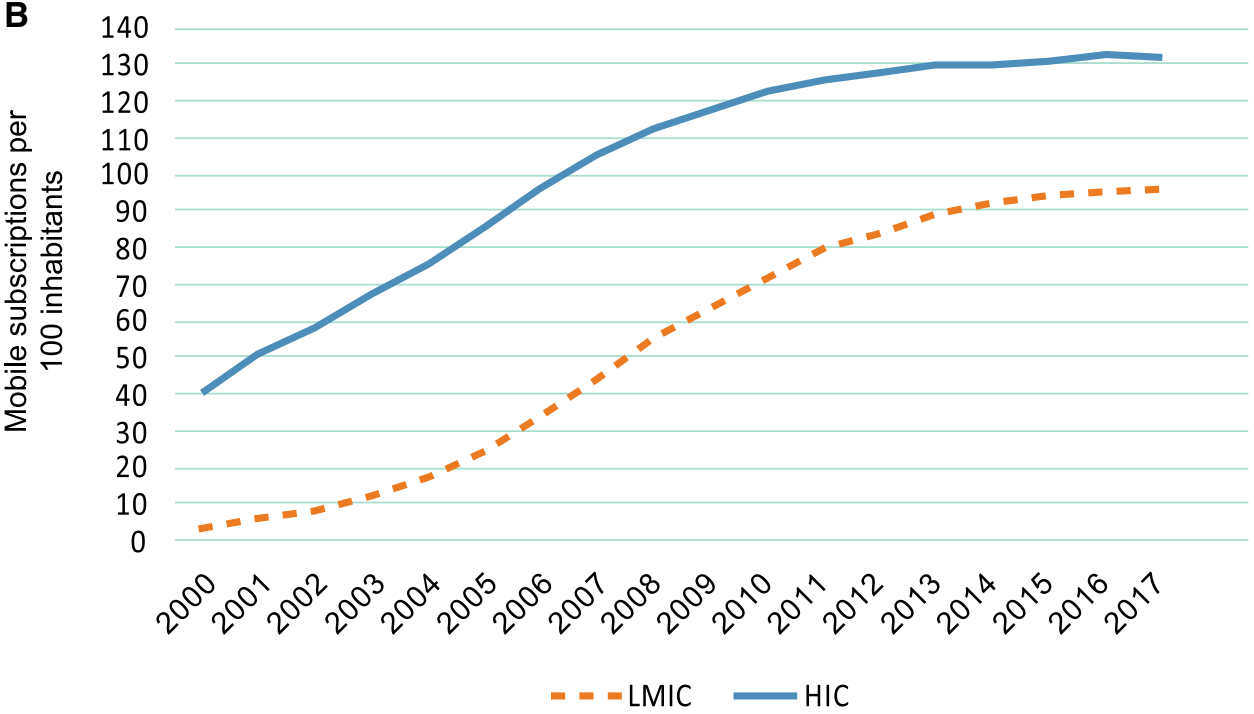


the implementation science research literature, feasibility is defined as the extent to which a treatment or innovation can be used or carried out by a specific agent or used successfully within a given context (Karsh, 2004; Proctor et al., 2011). Feasibility is conceptually linked to a number of other implementation outcomes, including the accessibility, affordability, acceptability/cultural appropriateness, and scalability of a treatment or innovation. Short definitions of these key implementation science terms as relevant to digital technologies are presented in Table 1.

Combining the global drive towards digital technologies for ASD, the fact that the majority of people with ASD live in LMIC, and the pre-existing digital divide as outlined by the World Bank, there is a significant risk that, without due reflection and consideration of the real-world feasibility of technologies, the global ASD community may increase this digital divide, and thus compound the well-known disparities that exist between HIC and LMIC in health, education, social integration and economic outcomes of families who live with ASD.

Here, we therefore set out to evaluate the six key technologies outlined earlier in terms of their overall feasibility for implementation in LMIC and low-resource contexts.

\section{Methods}

\section{Study Participants and Procedure}

A narrative feasibility evaluation was performed by three reviewers with clinical and research expertise in the use of technologies for ASD in LMIC. Each reviewer was provided with access to a recent review of digital technologies for autism, and to PDFs of all publications summarised in the background review of the six emerging technologies for ASD. After review of the literature each reviewer was asked to provide feasibility ratings of the implementation constructs selected.

\section{Implementation Science Constructs Evaluated}

In order to evaluate feasibility, four implementation constructs were selected for this study-acceptability, accessibility, appropriateness and scalability (see Table 1 for definitions). After rating each construct, reviewers were asked to provide an 'overall feasibility' judgment incorporating all constructs. In the absence of any existing criteria for feasibility rating of technologies, reviewers were asked to rate constructs as 'very low', 'low', 'high' or 'very high'. Reviewers were asked to provide comments and a narrative motivation for their ratings. The three reviewers were then asked to reach consensus on their feasibility rating for all categories through an iterative process until consensus was reached. Weighted kappa scores were calculated for initial ratings in relation to consensus ratings. Narrative comments were collated as collective motivation for final ratings.

\section{Results}

\section{Feasibility Evaluation of Technologies for ASD in LMIC}

\section{Categorical Ratings}

Figure 3 shows the consensus rating of each of the technologies in terms of their accessibility, affordability, acceptability/cultural appropriateness, scalability and overall feasibility in LMIC. Individual ratings showed weighted kappa scores of $0.714-1.000$ for accessibility, $0.850-1.000$ for affordability, 0.615-1.000 for acceptability/cultural appropriateness and $0.850-1.000$ for scalability. Overall feasibility showed weighted kappa scores ranging from $0.850-1.000$.

Table 1 Implementation constructs evaluated in this study in relation to digital technologies

\begin{tabular}{lll}
\hline Construct & Definition & Reference \\
\hline $\begin{array}{l}\text { Feasibility } \\
\text { Accessibility }\end{array}$ & $\begin{array}{l}\text { The extent to which a new technology can be used successfully within a given setting } \\
\text { The ease or difficulty for users to access a particular technology. Distance is often an important } \\
\text { indicator to measure the accessibility of resources }\end{array}$ & $\begin{array}{l}\text { Karsh (2004) } \\
\text { The true cost of implementing a particular technology. The construct depends on the costs of the } \\
\text { particular technology, the cost of implementation, and the cost of accessing the technology in a } \\
\text { particular location }\end{array}$ \\
$\begin{array}{l}\text { Acceptability and } \\
\text { cultural appropri- } \\
\text { ateness }\end{array}$ & $\begin{array}{l}\text { The perceived fit, relevance, or compatibility of the technology to a particular user, provider, com- } \\
\text { munity or setting }\end{array}$ & Proctor et al. (2011) \\
Scalability & $\begin{array}{l}\text { The ability of a technology (shown to be efficacious on a small scale and/or under controlled condi- } \\
\text { tions) to be expanded under real world conditions to reach a greater proportion of the eligible }\end{array}$ & Aarons et al. (2017) \\
population, while retaining effectiveness
\end{tabular}


Fig. 3 Feasibility of evidencebased technologies for autism spectrum disorder in low and middle-income countries (LMIC)

\begin{tabular}{|l|l|l|l|l|l|l|}
\hline Robotics & $\begin{array}{l}\text { Virtual } \\
\text { Reality }\end{array}$ & $\begin{array}{c}\text { Shared } \\
\text { Active } \\
\text { Surfaces }\end{array}$ & $\begin{array}{c}\text { Sensing } \\
\text { Technologies }\end{array}$ & $\begin{array}{c}\text { Personal } \\
\text { Computers }\end{array}$ & $\begin{array}{c}\text { Mobile } \\
\text { Technologies }\end{array}$ \\
\hline Accessibility & Very low & Low & Very low & Low & High & Very high \\
\hline Affordability & Very low & Low & Very low & Low & High & High \\
\hline $\begin{array}{l}\text { Acceptability } \\
\text { and cultural } \\
\text { appropriateness }\end{array}$ & Low & Low & High & High & High & Very high \\
\hline $\begin{array}{l}\text { Scalability } \\
\text { and sustainability }\end{array}$ & Very low & Low & Very low & Low & High & Very high \\
\hline $\begin{array}{l}\text { Overall feasibility } \\
\text { for use in } \\
\text { LMIC settings }\end{array}$ & Very low & Low & Low & Low & High & Very high \\
\hline
\end{tabular}

\section{Narrative Motivation for Feasibility Ratings}

\section{Accessibility}

As shown in Fig. 2, the 'digital divide' is strongly associated with the income classification of countries, and represents the gap between high-resource and low-resource settings in physical access to ICT and related skills/resources to use these technologies (Dutta et al., 2015; World Bank, 2016). However, access to and usage of technology is also associated with gender, level of education, literacy, urbanisation and socioeconomic status (Alozie \& Akpan-Obong, 2017; World Bank, 2016). In most LMIC, use of ICT is skewed towards young educated males of higher SES living in large towns or cities (Gomez, 2014; Wesolowski et al., 2015; World Bank, 2016). Even within LMIC there are therefore higher- and lower-resourced communities with differential access to technology. Most of the technologies reviewed here require access to reliable power supply. In sub-Saharan Africa $60 \%$ of people and in South-East Asia 30\% of people do not have direct access to electricity (World Bank, 2016). In addition, health services such as remote consultations utilising interactive video conferencing (telemedicine) depend on access to a $\mathrm{PC}$ and reliable internet connection with sufficient speed and bandwidth. Fewer than $25 \%$ of households in sub-Saharan Africa own a working computer, and even fewer connect to the internet using fixed (wired) broadband services (Gillwald, 2013; ITU, 2019). Access to PCs is becoming more widespread in LMIC as public access computing venues including libraries and internet cafes are being set up in many towns and villages (Gomez, 2014). In many underserved communities in Africa, mobile phone sharing or informal telecentres (where mobile phones can be used for a fee) are also improving access to ICT services. Close to $70 \%$ of people living in the poorest $20 \%$ of households globally have access to and are familiar with mobile phones (World Bank, 2016). Familiarity and proficiency with the technology are known to contribute to implementation success of technology-based healthcare initiatives (Zurovac et al., 2011, 2012). For these reasons, consensus ratings for accessibility were 'very high' for smartphone-based technologies, 'high' for personal computers, 'low' for sensing and virtual reality technologies, and 'very low' for robotics.

\section{Affordability}

As shown in Fig. 1, robots are by far the most expensive of the technologies reviewed here, ranging from several hundreds to upwards of thousands of US dollars, and typically require highly skilled technicians to operate and maintain them (Scassellati et al., 2012). Shared active surfaces and sensing technologies can also be very expensive, particularly when they require importing into LMIC. Costs associated with purchasing and installation of specialist equipment, software licencing, training and maintenance are likely to limit or even preclude the use of most technology platforms in LMIC community settings (Weiss et al., 2014). In most LMIC the internet connection speed and bandwidth required for technologies like telemedicine, IVC and VR are typically only available in large cities and can be up to four times more expensive than in HIC (ITU, 2016). It is also cheaper to access the internet using pre-paid mobile broadband data than fixed broadband services in these countries (ITU, 2016). Given the lower cost of android smartphones and greater access to cheaper mobile broadband services, an estimated 3.8 billion people worldwide were connecting 
to broadband internet services using their smartphones in 2019, 75\% of whom from LMIC (Groupe Spéciale Mobile Association, 2020). For these reasons consensus ratings for affordability were 'high' for smartphone-based technologies and personal computers, 'low' for sensing and virtual reality technologies, and 'very low' for shared active surfaces and robotics.

\section{Acceptability and Cultural Appropriateness}

Telemedicine can transport specialist clinicians virtually to meet with families in their homes in low-resourced communities where in-person care is not available. However, telemedicine may not be acceptable to all. Some cultural groups do not allow any photography or video recordings of people at all (Boujarwah et al., 2011) or disapprove of the use of mobile phones by women in public (Wei \& Kolko, 2005). In addition, it is not known how culturally acceptable virtual environments, the use of avatars, or participating in virtual reality-based activities would be in the culturally diverse communities in LMIC. Cultural beliefs often limit the adoption and use of technologies in LMIC (Bartneck et al., 2007; Rojas-Méndez et al., 2017). Many investigators of mHealth have highlighted the fact that access to mobile phones do not necessarily mean ownership of the device (Kumar et al., 2016). Sharing of or paying for mobile phone use is common practice and important in many African societies (Wesolowski et al., 2012). Ethical issues around confidentiality of health information and stigma therefore need careful consideration when determining if such services are appropriate and acceptable (Kaplan, 2006). However, given the increasing availability of cheaper mobile phones, the practice of sharing seems to be declining (Kumar et al., 2016; Wesolowski et al., 2015). Engaging the intended enduser community early should facilitate addressing local cultural, as well as practical challenges which may impede successful implementation (Grinker et al., 2012; Pickard et al., 2016). For these reasons, consensus ratings for acceptability/ cultural appropriateness were 'very high' for smartphonebased technologies, 'high' for personal computers, sensing technologies and shared active surfaces, and 'low' for virtual reality and robotics.

\section{Scalability}

Technology can potentially address many of the challenges faced by people with ASD who live in LMIC. Successful use of such tools will depend on it being effective, acceptable, affordable and-importantly-have the capacity to reach individuals in under-served areas and to be applied on a large scale in a variety of settings (Kazdin \& Rabbitt, 2013). A very overt aim of technology should therefore be to reach people wherever they are. Enabling community participation can further build capacity by increasing the number of people who can deliver services to those in need (Patel et al., 2008). Technology best suited to achieve this in LMIC would have to be familiar and widely used, not be dependent on uninterrupted electricity supply, and be able to receive and send information effectively and at low cost from almost anywhere. Advanced technologies such as VR and robotics typically require highly skilled people to operate and maintain them, as well as reliable and powerful internet and electricity infrastructure. Very high procurement and service costs are additional and important barriers to their widespread use. Even though PCs are increasingly accessible to many people in LMIC and telemedicine is gaining traction as a novel means of providing services to those in need who live in areas not well served by healthcare professionals, mobile phones today can perform most of the functions traditionally done on PCs. Accessing the internet via widely available mobile broadband services, using solar powered batteries to recharge the mobile phone's power supply, sharing of phones or informal telecentres represent some of the ways in which mobile phones can overcome many of the unique challenges faced in LMIC. The evolution of mobile technology, the ever-expanding mobile broadband network as well as phones and data becoming more affordable, gives mobile health (mHealth) the greatest scalability potential to expand the reach of health, educational and other services to those in need. For these reasons, consensus ratings for scalability were 'very high' for smartphone-based technologies, 'high' for personal computers, 'low' for sensing technologies, shared active surfaces and virtual reality, and 'very low' for robotics.

\section{Overall Feasibility}

Taking together all implementation-related constructs, consensus ratings for overall feasibility in LMIC were 'very high' for smartphone-based technologies, 'high' for personal computers, 'low' for sensing technologies, shared active surfaces and virtual reality technologies, and 'very low' for robotics.

\section{Discussion}

Digital technologies have a very significant potential to improve the lives of people who live with ASD, and an increasing volume of ASD technology research has emerged in recent years. The COVID-19 pandemic accelerated the drive towards remote technologies for all aspects of life across the globe. However, mindful that most people with ASD live in low- or middle-income countries (LMIC), and given the pronounced digital divide between highincome countries (HIC) and LMIC, we set out to explore 
the feasibility of implementing these technologies in LMIC settings. We selected four implementation constructsaccessibility, affordability, appropriateness, scalability-for consensus evaluation towards an overall feasibility rating. Review of the technologies identified and highlighted a range of exciting developments in ASD research over the last 2 decades. Feasibility ratings, however, showed how technologies had very different strengths and weaknesses across different implementation constructs when the 'implementation lens' was focused on LMIC contexts. Of all technologies examined, mobile/cellular technologies showed the most consistent 'high' and 'very high' ratings across implementation constructs and had the highest overall feasibility ratings for implementation in LMIC. Taken together, mobile technologies therefore seem to have the greatest potential to ensure we do not inadvertently increase the pre-existing digital disparities between individuals with ASD and their families who live in HIC versus LMIC.

The narrative findings of the study underlined the fundamental importance of the context for technology. Earlier work by Kientz et al., (2014) and Odom et al., (2015) recognised the importance of 'context' as a variable. However, previous research used the term to refer to home, school, clinic, research as 'context'. To date, no ASD technology research has used the term to refer to the macro-economic and/or cultural and linguistically diverse 'contexts' where people with ASD live. We propose to use the term 'setting' to refer to the specific place where a technology might be used (such as the school, home or clinic), and to use the term 'context' to refer to the broader socio/economic/cultural/linguistic environment into which a technology may be implemented. While robotics, shared active surfaces and virtual reality technologies may have significant potential application in various HIC contexts, the feasibility of implementation may look significantly different in LMIC contexts. It is laudable and important to examine how technology can be used to address the practical and day-to-day challenges of people who live with ASD. However, the global ASD community is culturally, linguistic, socio-economically and geographically immensely diverse. If our overarching goal is to address the disparities in access to ASD screening, diagnosis, and treatment between HIC and LMIC contexts using technology, these technologies need to be designed from the outset not only with the end-user, purpose, domain and setting in mind, but also with the accessibility, affordability, acceptability and scalability of the technology in the specific context and community of the end-user in mind. This highlights the need for all technological developments for ASD to include contextual implementation science evaluation (Proctor et al., 2011). Figure 4 represents our adaptation of the conceptual framework as presented by Odom et al., (2015) to incorporate the contextual implementation science lens (see Fig. 4). We propose that it is of fundamental

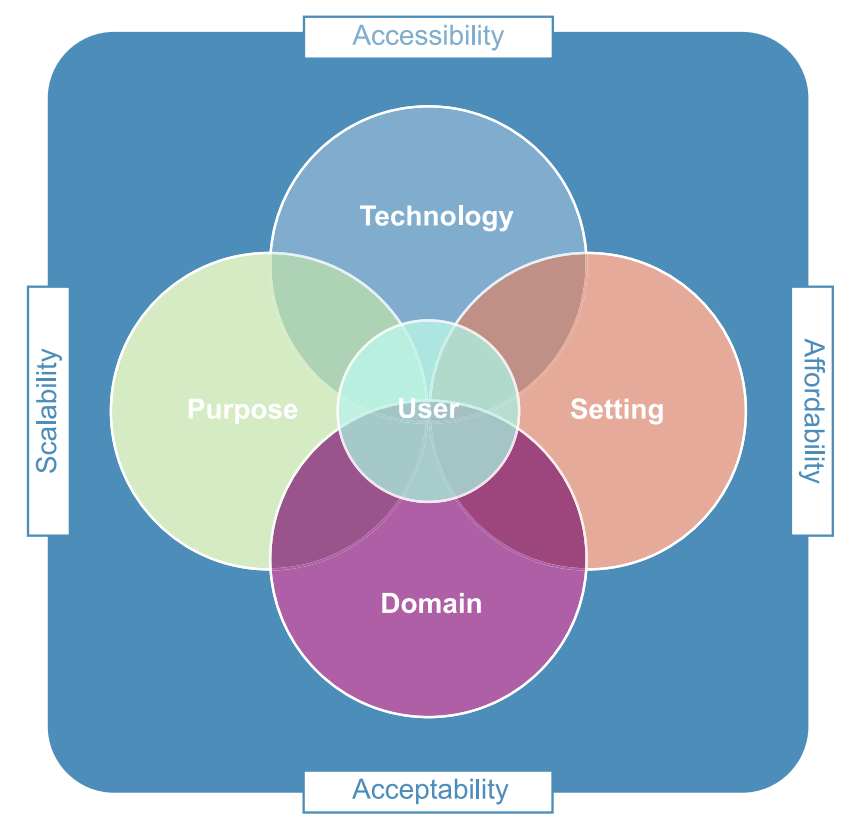

Fig. 4 Key considerations in the development of technologies for low- and middle-income countries

importance to incorporate this broader view of 'context' to ensure that our technological solutions reduce, rather than inadvertently increase, the digital divide.

\section{Limitations of the Study}

We acknowledge that this was a feasibility evaluation through expert consensus. The participants included only three expert reviewers based in the same global region. It is therefore possible that reviewers brought limited perspectives and their own biases that may have influenced overall feasibility ratings. However, reviewers represented three different professional groups, all had experience of working in multiple countries (across HIC and LMIC), all had expertise in technology and technology development for health applications, and weighted kappa values showed substantial agreement between raters and consensus. It would be very valuable for future studies to include stakeholders from diverse (but particularly LMIC) contexts. We further acknowledge that categorical ratings were performed without operationalised criteria. At present there are no global criteria for feasibility ratings of health technologies. For this reason, we included narrative comments to 'motivate' consensus ratings. Given the importance of the feasibility of technology, it may be helpful to develop a shared evaluation framework for technology in ASD, akin to the evaluation framework developed for parent education and training in ASD (Dawson-Squibb \& de Vries, 2019). Notwithstanding these limitations, this was the first study to our knowledge to perform feasibility rating of ASD technologies. We hope 
that our approach may stimulate reflection about these constructs in research.

\section{Conclusion}

Evidence-based technologies for ASD can play a tremendous role to ensure that the majority of people living in under-served areas have timely access to appropriate services and support. Digital technologies may therefore have utility for identification, diagnostic procedures, intervention, training and research in HIC and LMIC settings. Here we reflected on the feasibility of six examples of such technologies in LMIC contexts. Our findings suggest that feasibility of the use of such technologies in LMIC will depend on the fundamental principles of affordability, accessibility, acceptability and cultural appropriateness. These will determine the likely scale-up (increasing the reach in the community of interest) and scale-out (expanding the reach to new or different communities) (Aarons et al., 2017), and will ensure that we do not inadvertently exacerbate the pre-exisiting digital disparities between HIC and LMIC contexts.

Given the widespread usage of mobile and smartphones and the increasing availability of affordable high-speed mobile internet access in the majority of LMIC, mHealth has the greatest potential to increase access to ASD screening, diagnosis and treatment globally. However, the evidencebase for mobile technologies in LMIC settings remains extremely limited. For instance, there are almost no Apps for ASD to date that have been evaluated specifically for a LMIC context. To address this knowledge gap careful and nuanced research will be required to establish the feasibility of using mobile applications to provide access to quality health, educational and other services and care to the culturally, linguistic, socio-economically and geographically diverse global ASD community.

Author Contributions AJK and PJDV conceptualized and designed the study. AJK and MV collected and analyzed data. AJK and PJDV drafted and revised the manuscript. All authors read and approved the final manuscript.

\section{References}

Aarons, G. A., Sklar, M., Mustanski, B., Benbow, N., \& Brown, C. H. (2017). "Scaling-out" evidence-based interventions to new populations or new health care delivery systems. Implementation Science, 12(1), 111. https://doi.org/10.1186/s13012-017-0640-6

Alozie, N. O., \& Akpan-Obong, P. (2017). The digital gender divide: Confronting obstacles to women's development in Africa. Development Policy Review, 35(2), 137-160. https://doi.org/10.1111/ dpr.12204
Amaral, D. G., \& de Vries, P. J. (2020). COVID-19 and autism research: Perspectives from around the globe. Autism Research, 13(6), 844-869. https://doi.org/10.1002/aur.2329

American Psychiatric Association. (2013). Diagnostic and statistical manual of mental disorders: DSM-5. American Psychiatric Association.

Bakare, M. O., Agomoh, A. O., Ebigbo, P. O., Eaton, J., Okonkwo, K. O., Onwukwe, J. U., \& Onyeama, G. M. (2009). Etiological explanation, treatability and preventability of childhood autism: A survey of Nigerian healthcare workers' opinion. Annals of General Psychiatry, 8(1), 6. https://doi.org/10.1186/ 1744-859X-8-6

Bartneck, C., Suzuki, T., Kanda, T., \& Nomura, T. (2007). The influence of people's culture and prior experiences with Aibo on their attitude towards robots. AI \& SOCIETY, 21(1), 217-230. https:// doi.org/10.1007/s00146-006-0052-7

Bauminger-Zviely, N., Eden, S., Zancanaro, M., Weiss, P. L., \& Gal, E. (2013). Increasing social engagement in children with highfunctioning autism spectrum disorder using collaborative technologies in the school environment. Autism, 17(3), 317-339. https://doi.org/10.1177/1362361312472989

Ben-Sasson, A., Lamash, L., \& Gal, E. (2013). To enforce or not to enforce? The use of collaborative interfaces to promote social skills in children with high functioning autism spectrum disorder. Autism, 17(5), 608-622. https://doi.org/10.1177/13623 61312451526

Boccanfuso, L., Scarborough, S., Abramson, R. K., Hall, A. V., Wright, H. H., \& O'Kane, J. M. (2017). A low-cost socially assistive robot and robot-assisted intervention for children with autism spectrum disorder: Field trials and lessons learned. Autonomous Robots, 41(3), 637-655. https://doi.org/10.1007/ s10514-016-9554-4

Boujarwah, F. A., Hong, H., Abowd, G. D., Arriaga, R. I. (2011). Towards a framework to situate assistive technology design in the context of culture. Paper presented at the proceedings of the 13th international ACM SIGACCESS conference on Computers and accessibility. Doi: https://doi.org/10.1145/2049536.2049542

Bradshaw, J., Steiner, A. M., Gengoux, G., \& Koegel, L. K. (2015). Feasibility and effectiveness of very early intervention for infants at-risk for autism spectrum disorder: A systematic review. Journal of Autism and Developmental Disorders, 45(3), 778-794. https://doi.org/10.1007/s10803-014-2235-2

Cabibihan, J. J., Javed, H., Aldosari, M., Frazier, T. W., \& Elbashir, H. (2017). Sensing technologies for autism spectrum disorder screening and intervention. Sensors (Basel, Switzerland), 17(1), 46. https://doi.org/10.3390/s17010046

Colby, K. M. (1973). The rationale for computer-based treatment of language difficulties in nonspeaking autistic children. Journal of Autism and Childhood Schizophrenia, 3(3), 254-260. https://doi. org/10.1007/BF01538283

Colby, K. M., \& Smith, D. C. (1971). Computers in the treatment of nonspeaking autistic children. Current Psychiatric Therapies, $11,1-17$.

Constantino, J. N., Kennon-McGill, S., Weichselbaum, C., Marrus, N., Haider, A., Glowinski, A. L., Gillespie, S., Klaiman, C., Klin, A., \& Jones, W. (2017). Infant viewing of social scenes is under genetic control and is atypical in autism. Nature, 547(7663), 340-344. https://doi.org/10.1038/nature22999

Daley, T. C. (2004). From symptom recognition to diagnosis: Children with autism in urban India. Social Science and Medicine, 58(7), 1323-1335. https://doi.org/10.1016/S0277-9536(03)00330-7

Dautenhahn, K., \& Werry, I. (2004). Towards interactive robots in autism therapy: Background, motivation and challenges. Pragmatics \& Cognition, 12(1), 1-35. https://doi.org/10.1075/pc.12.1. 03dau 
David, D. O., Costescu, C. A., Matu, S., Szentagotai, A., \& Dobrean, A. (2020). Effects of a robot-enhanced intervention for children with ASD on teaching turn-taking skills. Journal of Educational Computing Research, 58(1), 29-62. https://doi.org/10.1177/ 0735633119830344

Dawson, G., Jones, E. J., Merkle, K., Venema, K., Lowy, R., Faja, S., Kamara, D., Murias, M., Greenson, J., Winter, J., Smith, M., Rogers, S. J., \& Webb, S. J. (2012). Early behavioral intervention is associated with normalized brain activity in young children with autism. Journal of the America Academy of Child \& Adolescent Psychiatry, 51(11), 1150-1159. https://doi.org/10.1016/j. jaac.2012.08.018

Dawson-Squibb, J. J., \& de Vries, P. J. (2019). Developing an evaluation framework for parent education and training in autism spectrum disorder: Results of a multi-stakeholder process. Journal of Autism and Developmental Disorders, 49(11), 4468-4481. https://doi.org/10.1007/s10803-019-04176-w

de Vries, P. J. (2016). Thinking globally to meet local needs: Autism spectrum disorders in Africa and other low-resource environments. Current Opinion in Neurology, 29(2), 130-136. https:// doi.org/10.1097/WCO.0000000000000297

Dickstein-Fischer, L., Alexander, E., Yan, X., Su, H., Harrington, K., \& Fischer, G. S. (2011). An affordable compact humanoid robot for Autism Spectrum Disorder interventions in children. IEEE Engineering in Medicine and Biology Society. Annual Conference, 2011, 5319-5322. https://doi.org/10.1109/IEMBS.2011.6091316

Dickstein-Fischer, L. A., Crone-Todd, D. E., Chapman, I. M., Fathima, A. T., \& Fischer, G. S. (2018). Socially assistive robots: current status and future prospects for autism interventions. Innovation and Entrepreneurship in Health, 5, 15-25. https://doi.org/10. 2147/IEH.S138753

Dickstein-Fischer, L. A., Pereira, R. H., Gandomi, K. Y., Fathima, A. T., \& Fischer, G. S. (2017). Interactive tracking for robotassisted autism therapy. Paper presented at the Proceedings of the Companion of the 2017 ACM/IEEE International Conference on Human-Robot Interaction, Vienna, Austria. https://doi.org/10. $1145 / 3029798.3038390$

Diehl, J. J., Schmitt, L. M., Villano, M., \& Crowell, C. R. (2012). The clinical use of robots for individuals with autism spectrum disorders: A critical review. Research in Autism Spectrum Disorders, 6(1), 249-262. https://doi.org/10.1016/j.rasd.2011.05.006

Dietz, P., \& Leigh, D. (2001). DiamondTouch: a multi-user touch technology. Paper presented at the Proceedings of the 14th annual ACM symposium on User interface software and technology. https://doi.org/10.1145/502348.502389

Divan, G., Vajaratkar, V., Desai, M. U., Strik-Lievers, L., \& Patel, V. (2012). Challenges, coping strategies, and unmet needs of families with a child with autism spectrum disorder in Goa, India. Autism Research, 5(3), 190-200. https://doi.org/10.1002/aur. 1225

Durkin, M. S., Elsabbagh, M., Barbaro, J., Gladstone, M., Happe, F., Hoekstra, R. A., \& Shih, A. (2015). Autism screening and diagnosis in low resource settings: Challenges and opportunities to enhance research and services worldwide. Autism Research, 8(5), 473-476. https://doi.org/10.1002/aur.1575

Dutta, S., Geiger, T., \& Lanvin, B. (2015). The Global Information Technology Report. ICTs for Inclusive Growth. Paper presented at the Geneva, World Economic Forum and INSEAD. Retrieved from http://www3.weforum.org/docs/WEF_Global_IT_Report_ 2015.pdf. (Accessed 21 Nov 2020)

Egger, H. L., Dawson, G., Hashemi, J., Carpenter, K. L., Espinosa, S., Campbell, K., \& Tepper, M. (2018). Automatic emotion and attention analysis of young children at home: A ResearchKit autism feasibility study. NPJ Digital Medicine, 1(1), 1-10. https://doi.org/10.1038/s41746-018-0024-6
Elsabbagh, M., Divan, G., Koh, Y. J., Kim, Y. S., Kauchali, S., Marcín, C., Montiel-Nava, C., Pate, V., Paula, C. S., Wang, C., Yasamy, M. T., \& Fombonne, E. (2012). Global prevalence of autism and other pervasive developmental disorders. Autism Research, 5(3), 160-179. https://doi.org/10.1002/aur.239

Facebook Technologies. (2021). Compare headsets. Retrieved from https://www.oculus.com/compare/. (Accessed 12 Jan 2021)

Farley, M. A., McMahon, W. M., JensonFombonne, W. R. E., Miller, J., Gardner, M., Block, H., Pingree, C. B., Ritvo, E. R., Ritvo, R. A., \& Coon, H. (2009). Twenty-year outcome for individuals with autism and average or near-average cognitive abilities. Autism Research, 2(2), 109-118. https://doi.org/10.1002/aur.69

Fletcher, R. R., Dobson, K., Goodwin, M. S., Eydgahi, H., WilderSmith, O., Fernholz, D., \& Picard, R. W. (2010). iCalm: Wearable sensor and network architecture for wirelessly communicating and logging autonomic activity. IEEE Transactions on Information Technology in Biomedicine, 14(2), 215-223. https:// doi.org/10.1109/titb.2009.2038692

Florida State University. (2021). Baby Navigator. Retrieved from https://babynavigator.com. (Accessed 6 Jan 2021)

Fombonne, E. (2009). Epidemiology of pervasive developmental disorders. Pediatric Research, 65(6), 591-598. https://doi.org/10. 1203/PDR.0b013e31819e7203

Franz, L., Chambers, N., von Isenburg, M., \& de Vries, P. J. (2017). Autism spectrum disorder in sub-saharan africa: A comprehensive scoping review. Autism Research, 10(5), 723-749. https:// doi.org/10.1002/aur.1766

Gal, E., Lamash, L., Bauminger-Zviely, N., Zancanaro, M., \& Weiss, P. L. (2016). Using multitouch collaboration technology to enhance social interaction of children with high-functioning autism. Physical \& Occupational Therapy in Pediatrics, 36(1), 46-58. https:// doi.org/10.3109/01942638.2015.1040572

Gartner. (2018). Gartner Says Worldwide Wearable Device Sales to Grow 26 Percent in 2019. https://www.gartner.com/en/newsr oom/press-releases/2018-11-29-gartner-says-worldwide-weara ble-device-sales-to-grow. (Accessed 22 Nov 2020)

Gentry, T., Wallace, J., Kvarfordt, C., \& Lynch, K. B. (2010). Personal digital assistants as cognitive aids for high school students with autism: Results of a community-based trial. Journal of Vocational Rehabilitation, 32(2), 101-107. https://doi.org/10.3233/ JVR-2010-0499

Gillwald, A. (2013). Towards an understanding of ICT access and use in Africa. Retrieved from https://www.researchictafrica.net/prese ntations/Presentations/2013\%20Gillwald\%20-\%20Towards\% 20an\%20understanding $\% 20$ of $\% 20 \% 20$ ICT $\% 20$ access $\% 20$ and $\%$ 20use\%20in\%20Africa.pdf. (Accessed 22 Nov 2020)

Gomez, R. (2014). When you do not have a computer: Public-access computing in developing countries. Information Technology for Development, 20(3), 274-291. https://doi.org/10.1080/02681102. 2012.751573

Goodwin, M. S., Groden, J., Velicer, W. F., Lipsitt, L. P., Baron, M. G., Hofmann, S. G., \& Groden, G. (2006). Cardiovascular arousal in individuals with autism. Focus on Autism and Other Developmental Disabilities, 21(2), 100-123. https://doi.org/10.1177/ 10883576060210020101

Goodwin, M. S., Intille, S. S., Albinali, F., \& Velicer, W. F. (2011). Automated detection of stereotypical motor movements. Journal of Autism and Developmental Disorders, 41(6), 770-782. https:// doi.org/10.1007/s10803-010-1102-z

Grinker, R. R., Chambers, N., Njongwe, N., Lagman, A. E., Guthrie, W., Stronach, S., Richard, B. O., Kauchali, S., Killian, B., Chhagan, M., Yucel, F., Kumudu, M., Baker-Cummings, C., Grether, J., \& Wetherby, A. M. (2012). "Communities" in community engagement: lessons learned from autism research in South 
Korea and South Africa. Autism Research, 5(3), 201-210. https:// doi.org/10.1002/aur.1229

Groupe Spéciale Mobile Association. (2020). The state of mobile internet connectivitiy 2020. Retrieved from https://www.gsma.com/r/ wp-content/uploads/2020/09/GSMA-State-of-Mobile-InternetConnectivity-Report-2020.pdf. (Accessed 23 Nov 2020)

Grynszpan, O., Weiss, P. L., Perez-Diaz, F., \& Gal, E. (2014). Innovative technology-based interventions for autism spectrum disorders: A meta-analysis. Autism, 18(4), 346-361. https://doi.org/ $10.1177 / 1362361313476767$

Harrison, A. J., Bradshaw, L. P., Naqvi, N. C., Paff, M. L., \& Campbell, J. M. (2017). Development and psychometric evaluation of the autism stigma and knowledge questionnaire (ASK-Q). Journal of Autism and Developmental Disorders, 47(10), 3281-3295. https://doi.org/10.1007/s10803-017-3242-x

Harrison, A. J., Long, K. A., Tommet, D. C., \& Jones, R. N. (2017). Examining the role of race, ethnicity, and gender on social and behavioral ratings within the autism diagnostic observation schedule. Journal of Autism and Developmental Disorders, 47(2), 2770-2782. https://doi.org/10.1007/s10803-017-3176-3

Hedges, S. H., Odom, S. L., Hume, K., \& Sam, A. (2018). Technology use as a support tool by secondary students with autism. Autism, 22(1), 70-79. https://doi.org/10.1177/1362361317717976

International Data Corporation (IDC). (2019). Worldwide Wearables Market to Top 300 Million Units in 2019 and Nearly 500 Million Units in 2023, Says IDC. Retrieved from https://www.idc. com/getdoc.jsp?containerId=prUS45737919. (Accessed 23 Nov 2020)

International Data Corporation (IDC). (2020). Low- to Mid-Range Smartphones Dominate Worldwide Smartphone Forecast with the Fastest Growth Expected in \$400-600 Price Band, According to IDC. Retrieved from https://www.idc.com/getdoc.jsp?conta inerId $=$ prUS46865120. (Accessed 23 Nov 2020)

International Telecommunication Union (ITU). (2010). ICT Facts and Figures 2010. Retrieved from https://www.itu.int/ITU-D/ict/ material/FactsFigures2010.pdf. (Accessed 23 Nov 2020)

International Telecommunication Union (ITU). (2016). ICT Facts and Figures 2016. Retrieved from https://www.itu.int/en/ITU-D/Stati stics/Documents/facts/ICTFactsFigures2016.pdf. (Accessed 23 Nov 2020)

International Telecommunication Union (ITU). (2019). Statistics. Global and Regional ICT Data (2005-2019). Retrieved fromhttps://www.itu.int/en/ITU-D/Statistics/Pages/stat/default.aspx. (Accessed 23 Nov 2020)

Kandalaft, M. R., Didehbani, N., Krawczyk, D. C., Allen, T. T., \& Chapman, S. B. (2013). Virtual reality social cognition training for young adults with high-functioning autism. Journal of Autism and Developmental Disorders, 43(1), 34-44. https://doi.org/10. 1007/s10803-012-1544-6

Kanne, S. M., Carpenter, L. A., \& Warren, Z. (2018). Screening in toddlers and preschoolers at risk for autism spectrum disorder: Evaluating a novel mobile-health screening tool. Autism Research, 11(7), 1038-1049. https://doi.org/10.1002/aur.1959

Kaplan, W. A. (2006). Can the ubiquitous power of mobile phones be used to improve health outcomes in developing countries? Globalization and Health, 2(1), 9. https://doi.org/10.1186/ 1744-8603-2-9

Karsh, B. T. (2004). Beyond usability: Designing effective technology implementation systems to promote patient safety. Quality and Safety in Health Care, 13, 388-394. https://doi.org/10.1136/qhc. 13.5.388

Kazdin, A. E., \& Rabbitt, S. M. (2013). Novel models for delivering mental health services and reducing the burdens of mental illness. Clinical Psychological Science, 1(2), 170-191. https://doi. org/10.1177/2167702612463566
Keusch, G. T., Wilentz, J., \& Kleinman, A. (2006). Stigma and global health: developing a research agenda. Lancet, 367(9509), 525527. https://doi.org/10.1016/S0140-6736(06)68183-X

Kientz, J. A., Goodwin, M. S., Hayes, G. R., \& Abowd, G. D. (2014). Interactive technologies for autism. Synthesis Lectures on Assistive, Rehabilitative, and Health-Preserving Technologies, 2(2), 1-177. https://doi.org/10.2200/S00533ED1V01Y201309A RH004

Kim, E. S., Berkovits, L. D., Bernier, E. P., Leyzberg, D., Shic, F., Paul, R., \& Scassellati, B. (2012). Social robots as embedded reinforcers of social behavior in children with autism. Journal of Autism and Developmental Disorders, 43(5), 1038-1049. https://doi.org/ 10.1007/s10803-012-1645-2

Koumpouros, Y., \& Kafazis, T. (2019). Wearables and mobile technologies in autism spectrum disorder interventions: A systematic literature review. Research in Autism Spectrum Disorders, 66, $1-25$.

Kumar, P., Paton, C., \& Kirigia, D. (2016). I've got 99 problems but a phone ain't one: Electronic and mobile health in low and middle income countries. Archives of Diseases in Childhood, 101(10), 974-979. https://doi.org/10.1136/archdischild-2015-308556

Kumazaki, H., Yoshikawa, Y., Yoshimura, Y., Ikeda, T., Hasegawa, C., Saito, D. N., \& Ishiguro, H. (2018). The impact of robotic intervention on joint attention in children with autism spectrum disorders. Molecular Autism, 9(1), 1-10. https://doi.org/10.1186/ s13229-018-0230-8

Lagunju, I. A., Bella-Awusah, T. T., \& Omigbodun, O. O. (2014). Autistic disorder in Nigeria: Profile and challenges to management. Epilepsy \& Behavior, 39, 126-129. https://doi.org/10. 1016/j.yebeh.2014.08.020

Law, G. C., Neihart, M., \& Dutt, A. (2018). The use of behavior modeling training in a mobile app parent training program to improve functional communication of young children with autism spectrum disorder. Autism, 22(4), 424-439. https://doi.org/10.1177/ 1362361316683887

Mahapatra, P., Pati, S., Sinha, R., Chauhan, A. S., Nanda, R. R., \& Nallala, S. (2019). Parental care-seeking pathway and challenges for autistic spectrum disorders children: A mixed method study from Bhubaneswar, Odisha. Indian Journal of Psychiatry, 61(1), 37-44. https://doi.org/10.4103/psychiatry.IndianJPsychiatry_ 257 18

Michels, K. M., Hofman, K. J., Keusch, G. T., \& Hrynkow, S. H. (2006). Stigma and global health: Looking forward. Lancet, 367(9509), 538-539. https://doi.org/10.1016/S0140-6736(06) 68190-7

Min, C. H., \& Tewfik, A. H. (2010). Automatic characterization and detection of behavioral patterns using linear predictive coding of accelerometer sensor data. Proceedings of the Annual International Conference of the IEEE Engineering in Medicine and Biology Society. IEEE Engineering in Medicine and Biology Society. Annual Conference, 2010: 220-223. https://doi.org/10. 1109/IEMBS.2010.5627850

Naslund, J. A., Aschbrenner, K. A., Araya, R., Marsch, L. A., Unutzer, J., Patel, V., \& Bartels, S. J. (2017). Digital technology for treating and preventing mental disorders in low-income and middle-income countries: A narrative review of the literature. Lancet Psychiatry, 4(6), 486-500. https://doi.org/10.1016/ S2215-0366(17)30096-2

Odom, S. L., Thompson, J. L., Hedges, S., Boyd, B. A., Dykstra, J. R., Duda, M. A., \& Bord, A. (2015). Technology-aided interventions and instruction for adolescents with autism spectrum disorder. Journal of Autism and Developmental Disorders, 45(12), 38053819. https://doi.org/10.1007/s10803-014-2320-6

Olusanya, B. O., Davis, A. C., Wertlieb, D., Boo, N. Y., Nair, M., Halpern, R., Kuper, H., Breinbauer, C., de Vries, P. J., Gladstone, M., 
Halfon, N., Kancherla, V., Mulaudzi, M. C., Kakooza-Mwesige, A., Ogbo, F. A., Olusanya, J. O., WrightWilliams, S. M. A. N., Manguerra, H.,... Kassebaum, N. J. (2018). Developmental disabilities among children younger than 5 years in 195 countries and territories, 1990-2016: A systematic analysis for the Global Burden of Disease Study 2016. The Lancet Global Health, 6(10), e1100-e1121. https://doi.org/10.1016/S2214-109X(18)30309-7

Olusanya, B. O., Wright, S. M., Nair, M. K. C., Boo, N.-Y., Halpern, R., Kuper, H., \& Kassebaum, N. J. (2020). Global burden of childhood epilepsy, intellectual disability, and sensory impairments. Pediatrics. https://doi.org/10.1542/peds.2019-2623

Parsons, D., Wilson, N. J., Vaz, S., Lee, H., \& Cordier, R. (2019). Appropriateness of the TOBY application, an iPad intervention for children with autism spectrum disorder: A thematic approach. Journal of Autism and Developmental Disorders, 49(10), 40534066. https://doi.org/10.1007/s10803-019-04115-9

Parsons, S., Leonard, A., \& Mitchell, P. (2006). Virtual environments for social skills training: Comments from two adolescents with autistic spectrum disorder. Computers \& Education, 47(2), 186206. https://doi.org/10.1016/j.compedu.2004.10.003

Parsons, S., Mitchell, P., \& Leonard, A. (2004). The use and understanding of virtual environments by adolescents with autistic spectrum disorders. Journal of Autism and Developmental Disorders, 34(4), 449-466. https://doi.org/10.1023/b:jadd.00000 $37421.98517 .8 \mathrm{~d}$

Patel, V., Flisher, A. J., Nikapota, A., \& Malhotra, S. (2008). Promoting child and adolescent mental health in low and middle income countries. Journal of Child Psychology and Psychiatry, 49(3), 313-334. https://doi.org/10.1111/j.1469-7610.2007.01824.x

Paul, R., Augustyn, A., Klin, A., \& Volkmar, F. R. (2005). Perception and production of prosody by speakers with autism spectrum disorders. Journal of Autism and Developmental Disorders, 35(2), 205-220. https://doi.org/10.1007/s10803-004-1999-1

Pickard, K. E., Wainer, A. L., Bailey, K. M., \& Ingersoll, B. R. (2016). A mixed-method evaluation of the feasibility and acceptability of a telehealth-based parent-mediated intervention for children with autism spectrum disorder. Autism, 20(7), 845-855. https:// doi.org/10.1177/1362361315614496

Pillay, S., Duncan, E. M., \& de Vries, P. J. (2021). Autism in the Western Cape province of South Africa: Rates, socio-demographics, disability and educational characteristics in one million school children. Autism, 25(4), 1076-1089. https://doi.org/10.1177/ 1362361320978042

Ploog, B. O., Scharf, A., Nelson, D., \& Brooks, P. J. (2013). Use of computer-assisted technologies (CAT) to enhance social, communicative, and language development in children with autism spectrum disorders. Journal of Autism and Developmental Disorders, 43(2), 301-322. https://doi.org/10.1007/ s10803-012-1571-3

POP Communications. (2020). How much should an interactive touchscreen solution cost?. https://www.popcomms.com/blog/muchinteractive-touchscreen-solution-cost/ (Accessed 23 Nov 2020)

Proctor, E., Silmere, H., Raghavan, R., Hovmand, P., Aarons, G., Bunger, A., \& Hensley, M. (2011). Outcomes for implementation research: Conceptual distinctions, measurement challenges, and research agenda. Administration and Policy in Mental Health, 38(2), 65-76. https://doi.org/10.1007/s10488-010-0319-7

Rogers, S. J., \& Dawson, G. (2010). Early start Denver model for young children with autism: Promoting language, learning, and engagement. Guilford Press.

Rogerson, J., Falkmer, M., Cuomo, B., Falkmer, T., Whitehouse, A. J. O., Granich, J., \& Vaz, S. (2019). Parental experiences using the therapy outcomes by you (TOBY) application to deliver early intervention to their child with autism. Developmental Neurorehabilitation, 22(4), 219-227. https://doi.org/10.1080/17518423. 2018.1440259
Rojas-Méndez, J. I., Parasuraman, A., \& Papadopoulos, N. (2017). Demographics, attitudes, and technology readiness. Marketing Intelligence \& Planning, 35(1), 18-39. https://doi.org/10.1108/ mip-08-2015-0163

Ruparelia, K., Abubakar, A., Badoe, E., Bakare, M., Visser, K., Chugani, D. C., Chugani, H. T., Donald, K. A., Wilmshurst, J. M., Shih, A., Skuse, D., \& Newton, C. R. (2014). Autism spectrum disorders in Africa: Current challenges in identification, assessment, and treatment a report on the international child neurology association meeting on ASD in Africa, Ghana, April 3-5. Journal of Child Neurology, 31(8), 1018-1026. https://doi.org/ 10.1177/0883073816635748

Saiano, M., Pellegrino, L., Casadio, M., Summa, S., Garbarino, E., Rossi, V., \& Sanguineti, V. (2015). Natural interfaces and virtual environments for the acquisition of street crossing and path following skills in adults with autism spectrum disorders: A feasibility study. Journal of Neuroengineering and Rehabilitation, 12(1), 17. https://doi.org/10.1186/s12984-015-0010-z

Sarker, H., Tam, A., Foreman, M., Fay, N., Dhuliawala, M., \& Das, A. (2018). Detection of stereotypical motor movements in autism using a smartwatch-based system. Annual Symposium Proceedings. AMIA Symposium, 2018, 952-960.

Saxena, S., Thornicroft, G., Knapp, M., \& Whiteford, H. (2007). Resources for mental health: scarcity, inequity, and inefficiency. Lancet, 370(9590), 878-889. https://doi.org/10.1016/ S0140-6736(07)61239-2

Scassellati, B. (2007). How social robots will help us to diagnose, treat, and understand autism. In S. Thrun, R. Brooks, \& H. Durrant-Whyte (Eds.), Robotics research. Springer tracts in advanced robotic (pp. 552-563). Berlin: Springer.

Scassellati, B., Admoni, H., \& Matarić, M. (2012). Robots for use in autism research. Annual Review of Biomedical Engineering, 14, 275-294. https://doi.org/10.1146/annur ev-bioeng-071811-150036

Silver, L. (2019). Smartphone ownership is growing rapidly around the world, but not always equally. Pew Research Center. https:// www.pewresearch.org/global/2019/02/05/smartphone-owner ship-is-growing-rapidly-around-the-world-but-not-alwaysequally/. (Accessed 30 Apr 2020)

Standen, P. J., \& Brown, D. J. (2005). Virtual reality in the rehabilitation of people with intellectual disabilities: Review. Cyberpsychology, Behavavior, and Social Networking, 8(3), 272-288. https://doi.org/10.1089/cpb.2005.8.272

Statista. (2020a). Average selling price of personal computers (PCs) worldwide from 2015 to 2019, in actual and constant currency. Retrieved from https://www.statista.com/statistics/722992/world wide-personal-computers-average-selling-price/. (Accessed 22 Nov 2020)

Statista. (2020b). Smartphone ownership rate by country 2018. https:// www.statista.com/statistics/539395/smartphone-penetrationworldwide-by-country/. (Accessed 22 Nov 2020)

Statista. (2021). Number of mHealth apps available in the Apple App Store from 1st quarter 2015 to 4th quarter 2020. Retrieved from https://www.statista.com/statistics/779910/health-apps-availableios-worldwide/https://www.statista.com/statistics/779919/healthapps-available-google-play-worldwide/. (Accessed 22 Nov 2020)

Stichter, J. P., Laffey, J., Galyen, K., \& Herzog, M. (2014). iSocial: Delivering the social competence intervention for adolescents (SCI-A) in a 3D virtual learning environment for youth with high functioning autism. Journal of Autism and Developmental Disorders, 44(2), 417-430. https://doi.org/10.1007/ s10803-013-1881-0

Travers, J. C., \& Fefer, S. A. (2016). Effects of shared active surface technology on the communication and speech of two preschool children with disabilities. Focus on Autism and Other 
Developmental Disabilities, 32(1), 44-54. https://doi.org/10. 1177/1088357615611390

van Schalkwyk, G. I., Marin, C. E., Ortiz, M., Rolison, M., Qayyum, Z., McPartland, J. C., \& Silverman, W. K. (2017). Social media use, friendship quality, and the moderating role of anxiety in adolescents with autism spectrum disorder. Journal of Autism and Developmental Disorders, 47(9), 2805-2813. https://doi.org/ 10.1007/s10803-017-3201-6

Vidal, M., Turner, J., Bulling, A., \& Gellersen, H. (2012). Wearable eye tracking for mental health monitoring. Computer Communications, 35(11), 1306-1311. https://doi.org/10.1016/j.comcom. 2011.11.002

Vismara, L. A., Young, G. S., Stahmer, A. C., Griffith, E. M., \& Rogers, S. J. (2009). Dissemination of evidence-based practice: Can we train therapists from a distance? Journal of Autism and Developmental Disorders, 39(12), 1636-1651. https://doi.org/10.1007/ s10803-009-0796-2

Warren, S. F., Gilkerson, J., Richards, J. A., Oller, D. K., Xu, D., Yapanel, U., \& Gray, S. (2010). What automated vocal analysis reveals about the vocal production and language learning environment of young children with autism. Journal of Autism and Developmental Disorders, 40(5), 555-569. https://doi.org/10. 1007/s10803-009-0902-5

Wei, C., \& Kolko, B. E. (2005). Studying mobile phone use in context: Cultural, political, and economic dimensions of mobile phone use. Paper Presented at the Professional Communication Conference. https://doi.org/10.1109/IPCC.2005.1494179

Weiss, P., Cobb, S., \& Zancanaro, M. (2014). Challenges in developing new technologies for special needs education: A force-field analysis. Paper presented at the 10th International Conference on Disability, Virtual Reality and Associated Technologies, Sweden. Retrieved from https://pdfs.semanticscholar.org/46f3/083aa3ebfd 6842503c443956c2488f49426a.pdf. (Accessed 30 Apr 2020)

Wesolowski, A., Eagle, N., Noor, A. M., Snow, R. W., \& Buckee, C. O. (2012). Heterogeneous mobile phone ownership and usage patterns in Kenya. PLoS ONE. https://doi.org/10.1371/journal. pone.0035319

Wesolowski, A., O’Meara, W. P., Tatem, A. J., Ndege, S., Eagle, N., \& Buckee, C. O. (2015). Quantifying the impact of accessibility on preventive healthcare in sub-Saharan Africa using mobile phone data. Epidemiology, 26(2), 223-228. https://doi.org/10. 1097/EDE.0000000000000239

Wetherby, A. M., Woods, J. J., Morgan, L., Holland, R. D., \& Wiseman, N. D. R. (n.d.). Autism Navigator. Retrieved from http://www. autismnavigator.com. (Accessed 29 Apr 2020)
Williams, L. W., Matson, J. L., Beighley, J. S., \& Konst, M. (2014). Ethnic disparities in early autism assessment: A large scale screening study of infants and toddlers. Journal of Developmental and Physical Disabilities, 27(2), 141-148. https://doi.org/10. 1007/s10882-014-9406-0

World Bank. (2016). World Development Report 2016-Digital Dividends. Retrieved from http://documents.worldbank.org/curated/ en/896971468194972881/pdf/102725-PUB-Replacement-PUBLIC.pdf. (Accessed 22 Nov 2020)

World Bank. (2020). Development Data Group. Income level/lowand middle-income countries. Retrieved from https://data.world bank.org/income-level/low-and-middle-income. (Accessed 22 Nov 2020)

World Health Organization. (2013). Meeting report: Autism spectrum disorders and other developmental disorders: From raising awareness to building capacity: World Health Organization, Geneva, Switzerland. Retrieved from https://apps.who.int/iris/ handle/10665/103312. (Accessed 22 Nov 2020)

Ye, Q., Deng, Z., Chen, Y., Liao, J., Li, G., \& Lu, Y. (2019). How resource scarcity and accessibility affect patients' usage of mobile health in China: Resource competition perspective. JMIR mHealth and uHealth. https://doi.org/10.2196/13491

Ye, Z., Li, Y., Fathi, A., Han, Y., Rozga, A., Abowd, G. D., \& Rehg, J. M. (2012). Detecting eye contact using wearable eye-tracking glasses. In Proceedings of the 2012 ACM Conference on Ubiquitous Computing (UbiComp '12). Association for Computing Machinery, New York, NY, USA, 699-704. https://doi.org/10. $1145 / 2370216.2370368$

Zurovac, D., Sudoi, R. K., Akhwale, W. S., Ndiritu, M., Hamer, D. H., Rowe, A. K., \& Snow, R. W. (2011). The effect of mobile phone text-message reminders on Kenyan health workers' adherence to malaria treatment guidelines: A cluster randomised trial. Lancet, 378(9793), 795-803. https://doi.org/10.1016/S0140-6736(11) 60783-6

Zurovac, D., Talisuna, A. O., \& Snow, R. W. (2012). Mobile phone text messaging: tool for malaria control in Africa. PLoS Medicine. https://doi.org/10.1371/journal.pmed.1001176

Publisher's Note Springer Nature remains neutral with regard to jurisdictional claims in published maps and institutional affiliations. 